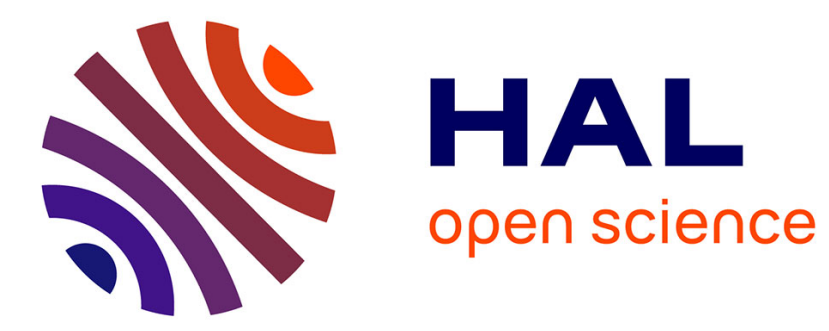

\title{
Behavior-based price discrimination and customer information sharing
}

Romain de Nijs

\section{To cite this version:}

Romain de Nijs. Behavior-based price discrimination and customer information sharing. 2015. hal01226250

\section{HAL Id: hal-01226250}

https://hal-polytechnique.archives-ouvertes.fr/hal-01226250

Preprint submitted on 9 Nov 2015

HAL is a multi-disciplinary open access archive for the deposit and dissemination of scientific research documents, whether they are published or not. The documents may come from teaching and research institutions in France or abroad, or from public or private research centers.
L'archive ouverte pluridisciplinaire HAL, est destinée au dépôt et à la diffusion de documents scientifiques de niveau recherche, publiés ou non, émanant des établissements d'enseignement et de recherche français ou étrangers, des laboratoires publics ou privés. 


\title{
ECOLE POLYTECHNIQUE
}

\section{Behavior-based price discrimination and customer information sharing}

\author{
Romain DE NIJS
}

October 28, 2015

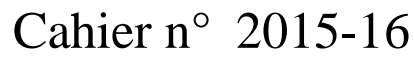

\section{DEPARTEMENT D'ECONOMIE}

Route de Saclay

91128 PALAISEAU CEDEX

(33) 169333033

http://www.economie.polytechnique.edu/

mariame.seydi@polytechnique.edu 


\title{
Behavior-based price discrimination and customer information sharing*
}

\author{
Romain De Nijs ${ }^{\dagger}$
}

October 28, 2015

\begin{abstract}
This article investigates the incentives and the effects of information sharing among rival firms about the identities of their past customers in a two-period model with behaviorbased price discrimination (BBPD). An unilateral information exchange between the two periods takes place in a subgame-perfect equilibrium. This exchange increases the ability of the industry to price discriminate consumers according to their profiles and boosts the profitability of BBPD at the expense of consumers.
\end{abstract}

Keywords: Price discrimination, Dynamic pricing, Privacy, Information sharing.

JEL: L1, D4

\section{Introduction}

In many markets, firms share individual-level customer information with their competitors. For example, in the grocery and drugstore markets, Catalina Marketing organizes information sharing of purchase history data among retailers to help them in designing their promotion campaigns (Pancras and Sudhir (2007)). Airline companies, through code-sharing agreements, exchange data on passengers to customize their services and prices (Czerny (2009)). One feature common to these examples ${ }^{1}$ is that information sharing tends to facilitate price discrimination.

${ }^{*}$ I thank Bernard Caillaud, Bruno Jullien, Philippe Février, Laurent Linnemer, Régis Renault and Jean Tirole for insightful discussions and comments. I also thank Cédric Argenton, Volker Nocke, Jérôme Pouyet, Patrick Rey, Idrissa Sibailly, Lars Stole, Luis Vasconcelos, J. Miguel Villas-Boas and seminar participants at Crest, the Ecole Polytechnique, and PSE for helpful discussions. I have benefited from funding by the Ecole des Ponts and the Haas School of Business. Any remaining errors are mine.

${ }^{\dagger}$ Department of Economics, Ecole Polytechnique, Palaiseau, France. email:romain.de-nijs@polytechnique.edu

${ }^{1}$ Sen Chen et al. (2001) and Liu and Serfes (2006) for other examples. 
Inspired by these examples, this article investigates a model in which firms can share their proprietary data on consumers when they compete with price discrimination and then evaluates the effects of such exchanges on market functioning. More specifically, I consider a two-period model in which firms that engage in behavior-based price discrimination (BBPD) in the second period may share their private information regarding the identities of their previous customers. $\mathrm{BBPD}$ is a very simple and common form of price discrimination that consists in offering different prices to different customers according to their past purchase history.

Information exchanges on consumer identities have two potential effects. A first static effect occurs in the mature phase of a market: information exchanges enable firms to more finely price discriminate their customers and hence have a priori ambiguous effects on firms profits. The second dynamic effect is fostered by the prospect of future information exchange that modifies the incentives of firms to initially acquire information on their consumers in a new market. I am interested in understanding these two effects of information exchanges and their consequences on firms profits and consumers surplus.

To investigate these issues, I study a two-period model with repeated purchases and three rival firms that compete on price to sell horizontally differentiated goods. Each firm offers a product that matches a consumer's preferences with a certain probability. Consumers fall into four segments, depending on the number of products they value: consumers who value no product, captive consumers who value only one product, local shoppers who value two products and global shoppers who value all three of the products. In the first period, there is no purchase history; therefore, firms use uniform prices. In the first-period, firms set their prices according to an absolutely continuous price distribution so that they can be ranked ex post according to said prices. The highest-price firm (hereafter the small firm) serves only its captive consumers. The intermediate-price firm (hereafter the medium firm) serves its captive consumers and the local shoppers between its product and that of the small firm. The lowest-price firm (hereafter the large firm) serves all the other consumers. In the second period, firms can recognize their past customers and charge them a different price than they charge their new customers. When information sharing is allowed, each firm decides between the two periods whether to sell its list of past customers and its price, as well which databases sold by its rivals it purchases. Depending on which additional customer lists a firm has acquired, it can eventually more finely price discriminate among consumers in the second period.

I show that customer information sharing between rival firms takes place in a subgame perfect equilibrium and that it increases the profitability of BBPD at the expense of consumers 
in both periods. In the terminology of Liu and Serfes (2006), there is a "one-way information sharing" from the medium or the large firm to the small one. The acquisition of this new information increases the surplus extraction power of the small firm, which is then able to offer three different prices - one price for each firm's previous customers - as opposed to just two prices in the absence of information sharing. Information sharing clearly benefits the small firm but does not hurt the profits of the medium firm or the large firm. This corresponds to the static effect of information sharing. Because they do not suffer from information sharing in the second period, both the medium and the large firms are then willing to sell the identity of their previous customers to the small firm between the two periods. The small firm only needs one additional customer list from either the medium or the large firm to more finely price discriminate consumers, so that direct competition between the medium and the large firms leads them to sell their databases at a price equal to zero. However, all firms benefit from information sharing across the entire game because information sharing further increases the profit of the small firm in the second period. This phenomenon reinforces the incentives of firms to charge a high price in the first period to secure the small firm position. The first period competition is therefore softer with the prospect of BBPD and information sharing than with BBPD alone: firms' profits increase and consumer surplus decreases. This corresponds to the dynamic effect of information sharing.

This article is firstly related to a recent vein of research that studies information sharing among rival firms in dynamic frameworks for price discrimination purposes ${ }^{2}$. Liu and Serfes $(2006)^{3}$ investigate a two-period duopoly model, with perfect price discrimination in the second period based on first-period information. They show that information sharing occurs if firms are sufficiently asymmetric in their customer bases. With sufficient asymmetry, the smaller firm has an incentive to share its customer information with the larger one. My model gives a different prediction in that the shared information goes from one of the two largest firms to the smallest firm. In addition, I consider that firms can only condition their prices on past purchase histories and, hence, cannot perfectly price discriminate as in Liu and Serfes (2006). Kim and Choi (2010) study a two-period model with BBPD and information sharing that reveals whether the rival products are complement or are substitute for each other. In the current analysis, firms know that their products are substitutes, and information sharing enables them to refine their knowledge regarding each consumer's preferences. Shy and Stenbacka (2013) investigate

\footnotetext{
${ }^{2}$ See Taylor (2004) and Calzoni and Pavan (2006) for information sharing among non-rival firms.

${ }^{3}$ See Liu and Serfes (2004) who also endogenize the information used by firms to engage in price discrimination in an initial investment stage.
} 
how information exchange affects the incentives of firms to invest in the costly acquisition of information on customers tastes. They show that the exchange of acquired information is bad for firms' profits and hurts consumers, but that such exchanges do not occur in equilibrium. The current analysis is also related to articles on information sharing for price discrimination purposes in static frameworks ${ }^{4}$. (See Chen et al. (2001), Shy and Stenbacka (2012), and Jentzsch et al. (2013)).

This article is also related to the literature on competitive BBPD pioneered by Chen (1997), Villas-Boas (1999) and Fudenberg and Tirole (2000) (See Chen (2005), Fudenberg and VillasBoas (2007), and Esteves (2009b) for surveys). Technically, the current model builds on those of Esteves (2009a) and Chen and Zhang $(2009)^{5}$, by including one additional firm and introducing the possibility for firms to exchange their databases. As further discussed in the analysis, the current article is also importantly related to Esteves and Vasconcelos (2014) who investigate BBPD and mergers in a triopoly model. My model differs in that I consider a different segmentation of consumers and study information sharing rather than merger. In terms of results, I show that without merger or information sharing, BBPD is still profitable thanks to the presence of local shoppers. I also show that information sharing is an equilibrium outcome with anticompetitive effects which is not the case in the environment of Esteves and Vasconcelos (2015).

The rest of this article is organized as follows. Section 2 presents the model. Section 3 investigates the case of competition with BBPD but without information sharing. Section 4 considers competition with BBPD and information sharing. Sections 5 concludes. All missing proofs are relegated in an appendix.

\section{The model}

Consider a model with two periods of consumption and repeated purchases. There is a mass one of consumers willing to buy at most one product each period. A consumer derives a utility $v>0$ if the product matches her preferences and 0 otherwise. There are 3 firms $\mathrm{i}=1,2$ and 3 , that compete on price. Each firm provides a good that matches a consumer's preferences with a probability $^{6} \theta \in[0,1]$. Consequently, each firm has a base $\theta(1-\theta)^{2}$ of captive consumers

\footnotetext{
${ }^{4}$ There also exists a branch of the literature on evaluations of information exchanges in credit markets (See for instance Pagano and Jappelli (1993), Padilla and Pagano (1997, 2000), and Gehrig and Stenbacka (2007))

${ }^{5}$ See also Caillaud and De Nijs (2014) and De Nijs (2013) for related models, and Esteves (2010) for another model of BBPD with discrete consumer preferences.

${ }^{6}$ Chen and He (2011) make similar assumptions.
} 
who only consider its product. Each pair of firms has a fraction $\theta^{2}(1-\theta)$ of consumers who consider only their two products (hereafter local shoppers). Last, a fraction $\theta^{3}$ of consumers consider the three products as suitable (hereafter global shoppers). Consumers are myopic: they only care about the price to be paid in the current period. Hence, they buy in each period the lowest-price product that match their preferences.

Forward-looking firms have zero marginal costs and a discount factor equal to one ${ }^{7}$. In the first period, firms use uniform prices. In the second period, when information sharing is not allowed, firms can engage in BBPD by charging a different price to their new and past customers. When information sharing is allowed, each firm decides simultaneously between the two periods whether and at which prices to sell its entire list of past customers, as well as, which databases sold by its rivals it purchases. Depending on which additional customer lists a firm has acquired, a firm can eventually more finely price discriminate among consumers in the second period.

Direct application of Stahl (1994) with exogenous consumer segmentation shows that when $\mathrm{BBPD}$ is not allowed, there exists a symmetric equilibrium in which in each period, firms randomize their price according to the cumulative distribution function $(\mathrm{cdf}) F_{u p}(p)=1-$ $\frac{1-\theta}{\theta}\left(\left(\frac{v}{p}\right)^{1 / 2}-1\right)$ with support $\left[\underline{p}_{u p}=(1-\theta)^{2} v, v\right]$. Each firm earns an expected profit $\theta(1-\theta)^{2} v$ per period. As a consequence, in the benchmark case of uniform price competition, each firm earns a total expected profit $\Pi_{u p}^{t o t}=2 \theta(1-\theta)^{2} v$.

\section{BBPD without information sharing}

\subsection{Second period}

Define $p_{i, t}$ as firm $i$ 's price at period $t$. Without loss of generality, assume that $p_{1,1}>p_{2,1}>p_{3,1}^{8}$. In this case, firm 1 (hereafter the small firm) has served only its captive consumers, and can perfectly recognize them in the second period. Firm 2 (hereafter the medium firm) has served both its captive consumers and local shoppers between products 1 and 2. Firm 2 has therefore only partially told apart its segment of captive customers. Firm 3 (hereafter the large firm) has served all other consumers and hence has learned nothing about the type of its customers. Each firm is potentially able to charge one price to its past customers and one price to its new consumers. However, the large firm has served all its potential consumers in the first period.

\footnotetext{
${ }^{7}$ Considering a discount factor smaller than one adds notation without any additional result.

${ }^{8}$ The probability of a tie in prices is zero in any first-period equilibrium (See Section 3.2), and one can always renumber firms.
} 
Consequently, the large firm cannot attract new customers and hence, charges only one price to its past customers.

Proposition 1 In the second period when $B B P D$ is allowed, there exists an equilibrium in which:

- The small firm charges its past customers the price $v$ and charges its new customers a price randomized according to the cumulative distribution function (cdf) $F_{s}^{n}(p)=1-\frac{1-\theta}{\theta}\left(\frac{v}{p}-1\right)$ on $[\underline{p}=(1-\theta) v, v]$

- The medium firm charges its past customers a price randomized according to the cdf $F_{m}^{o}(p)=1-\frac{(1-\theta) v}{p}$ on $[(1-\theta) v, v[$ with a mass $(1-\theta)$ on $v$; and charges its new customers a price randomized according to the cdf $F_{m}^{n}(p)=1-\frac{1-\theta}{\theta}\left(\frac{(1-\theta) v}{p}-1\right)$ on $\left[\underline{\underline{p}}=(1-\theta)^{2} v,(1-\theta) v\right]$.

- The large firm randomizes its price according to the cdf $F_{l}^{o, n}(p)=1-\frac{(1-\theta)^{2} v}{p}$ on $\left[(1-\theta)^{2} v, v\right]$ with a mass $(1-\theta)^{2}$ on $v$.

Firms' second-period expected profits are:

$\Pi_{s}=\theta(1-\theta)^{2} v+\theta(1-\theta)^{2}\left(1-(1-\theta)^{2}\right) v$ for the small firm.

$\Pi_{m}=\theta(1-\theta)^{2} v+\theta(1-\theta)^{2}(1-(1-\theta)) v$ for the medium firm.

$\Pi_{l}=\theta(1-\theta)^{2} v$ for the large firm.

The first term in expected profits $\theta(1-\theta)^{2} v$ is the profit each firm can guarantee itself by charging the monopoly price on its base of captive consumers. It also corresponds to the one-period profit under uniform price competition (Stahl (1994)). The second term is the extra profit a firm derives from its ability to price discriminate. It is immediate to check that $\Pi_{s}>\Pi_{m}>\Pi_{l}$ so that a firm derives a higher profit when it has more accurately recognized its segment of captive consumers. A firm is said to have more accurately recognized its captive consumers when it can build a smaller list of consumers that contains its captive consumers. The small firm has perfectly recognized its captive consumers, as its list of past customers contains only its captive consumers. The medium firm has only imperfectly recognized its captive consumers because its list of past customers contains both its captive consumers and local shoppers with the small firm. However, the medium firm has more accurate information about its captive consumers than the large firm, whose list of past customers contains all of its potential customers.

Proposition 1 shows that the profitability of BBPD studied by Esteves (2009a) and Chen and Zhang (2009) can survive in a model with more than 2 firms. However, it contrasts with some 
results of Esteves and Vasconcelos (2015) who study BBPD and mergers in a triopoly model with captive consumers and global shoppers. Among other things, they show that (without merger) firms earn the same profits with or without BBPD. This result occurs because, in the second period, discriminating firms compete à la Bertrand for price-sensitive consumers. As a consequence, they make no extra profits from their ability to price discriminate. In the current article, there is no full-fledged competition effect because there are always consumers with only two firms offering a good they value, namely local shoppers. Consequently, in the second period, discriminating firms have market power on a fraction of price-sensitive consumers from rivals, and hence, can derive extra profits from their ability to price discriminate ${ }^{9}$.

As usually found in the literature on BBPD without long-term contract, discriminating firms offer higher prices to their past customers who have revealed a stronger preference for the firm's product ${ }^{10}$. Here, a novelty arises for the small firm: it randomly draws the price it charges to its new customers on the interval $[(1-\theta) v, v]$. Doing so, it specifically targets local shoppers with the medium firm's product and local shoppers with the large firm's product. The small firm indeed has no chance to attract global shoppers because the medium firm randomly chooses the price it charges to its new customers (among which are the global shoppers) on the interval $\left[(1-\theta)^{2} v,(1-\theta) v\right]$ which is below the interval $[(1-\theta) v, v]$.

The equilibrium described in Proposition 1 still exists with forward-looking consumers as long as their discount factor is low enough. The proof is available upon request.

\subsection{First period}

In the first period, a firm makes its pricing decision rationally anticipating how this decision affects its current and future profits. One can show that there exists no pure-strategy equilibrium, but a symmetric mixed-strategy equilibrium exists in which firms mix their price according to a cdf $F_{p d}($.$) on \left[\underline{p}_{p d}, v\right]$. The total expected profit of a firm that charges a price $p$ in the first period then writes:

$$
\Pi_{p d}^{t o t}(p)=p \theta\left(1-\theta F_{p d}(p)\right)^{2}+\left(1-F_{p d}(p)\right)^{2} \Pi_{l}+2\left(1-F_{p d}(p)\right) F_{p d} \Pi_{m}+F_{p d}^{2}(p) \Pi_{s}
$$

The first term is identical to that of the benchmark case with uniform pricing (Stahl (1994)). The other terms correspond to the profit a firm will earn in the second period according to

\footnotetext{
${ }^{9}$ See Taylor (2003) and Chen (2005) for a similar argument in markets with switching costs.

${ }^{10}$ For model with rewards for past customers, see Shaffer and Zhang (2000), Shin and Sudhir (2010), Caillaud and De Nijs (2014), and De Nijs and Rhodes (2013) when firms cannot commit to future prices, and Chen and Pearcy (2010) when firms can use long-term contracts.
} 
its first-period price ranking. For instance, with a probability $\left(1-F_{p d}(p)\right)^{2}$ a firm charges the lowest first-period price and hence, earns $\Pi_{l}$ in the second period. Because a firm must be indifferent between all prices in the support of $F_{p d}($.$) , one has \Pi_{p d}^{t o t}(p)=\Pi_{p d}^{\text {tot }}(v)=2 \theta(1-\theta)^{2} v+$ $\theta(1-\theta)^{2}\left(1-(1-\theta)^{2}\right) v$ for all $p \in\left[\underline{p}_{p d}, v\right]$. This equality gives $F_{p d}($.$) . The regularity condition$ $F\left(\underline{p}_{p d}\right)=0$ yields: $\underline{p}_{p d}=(1-\theta)^{2}\left(2-(1-\theta)^{2}\right) v$. The formal proof for Proposition 3 is a direct application of Varian (1980) and Narasimhan (1988) and is therefore omitted.

Proposition 2 When BBPD is allowed in the second period, there is a symmetric price equilibrium in the first period in which each firm randomizes its price according to the cdf: $F_{p d}(p)=$ $1-\frac{1-\theta}{\theta}\left(\left(\frac{\left(1-(1-\theta)^{2}\right) v}{p-(1-\theta)^{2} v}\right)^{1 / 2}-1\right)$ on $\left[\underline{p}_{p d}=(1-\theta)^{2}\left(2-(1-\theta)^{2}\right) v, v\right]$. Each firm earns an total expected profit $\Pi_{p d}^{\text {tot }}=2 \theta(1-\theta)^{2} v+\theta(1-\theta)^{2}\left(1-(1-\theta)^{2}\right) v$.

The first term $2 \theta(1-\theta)^{2} v$ in the expected profit $\Pi_{p d}^{t o t}$ is the guaranteed profit each firm would derive in a two-period game with uniform pricing. The second term $\theta(1-\theta)^{2}\left(1-(1-\theta)^{2}\right) v$ is the extra profit each firm expects to earn thanks to BBPD, viewed from the beginning of the game. It is simple to check that $F_{p d}($.$) has first-order stochastic dominance over F_{u p}($.$) . This$ property clearly delineates the incentive firms have to price high in the first period to more accurately recognize their captive consumers. This "race for discrimination effect" has first been identified and investigated by Esteves (2009a) and Chen and Zhang (2009) in duopoly markets. Because BBPD is profitable in the second period of the current model, the "race for discrimination effect" is also present, whereas it is not the case in Esteves and Vasconcelos (2009).

\section{BBPD with information sharing}

\subsection{Equilibrium in the second period}

Assume that $p_{1,1}>p_{2,1}>p_{3,1}$. The only firm that is likely to be interested in acquiring customers lists from its rivals is the small firm (firm 1). Indeed, if the small firm learns the identities of its rivals' past customers, it is then able to charge three different prices (instead of two): one price for its own past customers and one price for each of the other two firms' past customers. The medium firm (firm 2) is not interested in acquiring information regarding the small firm's past customers' identities because these consumers do not value its product. In addition, firm 2 does not value the customers list of the large firm because this list would not allow it to more finely price discriminate consumers. Last, the large firm does not value 
the small and the medium firms' past customer lists because these customers do not value its product. Therefore, I consider the scenario in which the small firm has acquired the list of past customers of either the medium or the large firm.

Proposition 3 In the second period, when BBPD is allowed and the small firm has acquired the list of past customers of the medium or the large firm, there exists an equilibrium in which:

- The small firm charges its past customers a price $v$, randomizes its prices to the medium firm's past customers according to the $c d f F_{s}^{m}(p)=1-\frac{1-\theta}{\theta}\left(\frac{v}{p}-1\right)$ on $[(1-\theta) v, v]$, and randomizes its price to the large firm's past customers according to the $\operatorname{cdf} F_{s}^{l}(p)=$ $1-\frac{1-\theta}{\theta}\left(\left(\frac{v}{p}\right)^{1 / 2}-1\right)$ on $\left[(1-\theta)^{2} v, v\right]$.

- The medium firm randomizes its price to its past customers according to the $\operatorname{cdf} F_{m}^{m}(p)=$ $1-\frac{(1-\theta) v}{p}$ on $[(1-\theta) v, v]$, with a mass $(1-\theta)$ on $v$, and randomizes its price to the large firm's past customers according to the $\operatorname{cdf} F_{m}^{l}(p)=1-\frac{1-\theta}{\theta}\left(\left(\frac{v}{p}\right)^{1 / 2}-1\right)$ on $\left[(1-\theta)^{2} v, v\right]$.

- The large firm randomizes its price to its past customers according to the $\mathrm{cdf} F_{l}^{l}(p)=$ $1-(1-\theta)\left(\frac{v}{p}\right)^{1 / 2}$ on $\left[(1-\theta)^{2} v, v\right]$ with a mass $(1-\theta)$ on $v$.

Firms' second-period expected profits are:

$\tilde{\Pi}_{s}=\theta(1-\theta)^{2} v+2 \theta^{2}(1-\theta)^{2} v$ for the small firm.

$\tilde{\Pi}_{m}=\theta(1-\theta)^{2} v+\theta^{2}(1-\theta)^{2} v$ for the medium firm.

$\tilde{\Pi}_{l}=\theta(1-\theta)^{2} v$ for the large firm.

In comparison to competition with uniform pricing, the small and the medium firms earn an additional profit $\theta^{2}(1-\theta)^{2} v$ from each sub market of past customers of their rivals wherein they compete. In comparison to competition with BBPD but without information sharing, the small firm earns an additional profit $\theta^{3}(1-\theta)^{2} v$ and the medium and the large firms earn the same profits.

To increase its profit, the small firm only needs to acquire the list of past customers of the medium or the large firm. Consequently, the medium and the large firm compete à la Bertrand to sell their customer lists to the small firm so that they offer their lists of past customers at a price equal to zero. Therefore in equilibrium, information sharing occurs from the medium or the large firm to the small firm, and total industry profits increase with respect to the situation with BBPD and no information sharing. Last, as the total welfare is fixed to $\left(1-(1-\theta)^{3}\right) v$ by period in this model, consumers are hurt by information sharing in the second period. 
Proposition 4 There exits an equilibrium in which the small firm acquired the list of past customers of the medium or the large firm at a price equal to zero. This information sharing increases the second-period industry profits at the expense of consumers.

It is interesting to compare the effects of information sharing with those of mergers as in Esteves and Vasconcelos (2015). In the current model it is possible to find a two-firm merger that is more profitable that information sharing. Indeed, consider the situation in which the small and the medium firms merge at the beginning of the second period. In the second period of the game, the merging entity uses three prices: one price $v$ charged to their $2 \theta(1-\theta)^{2}+\theta^{2}(1-\theta)$ common past customers, one price charged by the small firm to the past customers of the large firm, and one price charged by the medium firm to the past customers of the large firm. Application of Proposition 3 shows that the merging entity makes a profit $2 \theta^{2}(1-\theta)^{2} v$ from past customers of the large firm. The bottom line, is that the merging entity makes a total second-period profit equal to $2 \theta(1-\theta)^{2}+\theta^{2}(1-\theta)+2 \theta^{2}(1-\theta)^{2} v$ which is greater that the joint profit of the small and the medium firms with information sharing which is equal to $2 \theta(1-\theta)^{2}+\theta^{2}(1-\theta)^{2}+2 \theta^{2}(1-\theta)^{2} v$. This implies that information sharing is less detrimental than a merger for consumers. However, in contrast to Esteves and Vasconcelos (2015), information sharing has still substantial anticompetitive effects.

\subsection{First period}

In the first period, firms rationally anticipate future information sharing and BBPD. A similar reasoning than in the case of $\mathrm{BBPD}$ without information sharing leads to Proposition 5 . The formal proof for Proposition 5 is a direct application of Varian (1980) and Narasimhan (1988) and is therefore omitted.

Proposition 5 When BBPD and information sharing are allowed in the second period, there is a symmetric price equilibrium in the first period in which each firm randomizes its price according to the cdf: $F_{p d, i s}(p)=\frac{p-(1-\theta) v-(1-\theta)\left(\left((1-\theta)^{2} v+(2 \theta-1) p\right) v\right)^{1 / 2}}{\theta p}$ on $\left[\underline{p}_{p d, i s}=(1+2 \theta)(1-\theta)^{2} v, v\right]$. Each firm earns an expected total profit $\Pi_{p d, i s}^{\text {tot }}=2 \theta(1-\theta)^{2} v+2 \theta^{2}(1-\theta)^{2} v$.

Viewed from the beginning of the game, all firms benefit in expectation from future information with BBPD, even if, only one of them will eventually be the second-period small firm that actually increases its profits thanks to information exchange. One can easily show that $F_{p d, i s}($.$) has first-order stochastic dominance over F_{p d}($.$) . This property shows that the$ "race for discrimination" is exacerbated when information sharing occurs on top of BBPD in 
the second period. This is because the small firm position becomes even more profitable with information sharing. This dynamic effect of information sharing is similar to the first-period effect of merger studied by Esteves and Vasconcelos (2015). If consumers were forward-looking, the equilibrium described in Proposition 5 might be disrupted by strategic behaviors of consumers. Indeed, forward-looking consumers might want to make different purchasing decisions than myopic consumers to manipulate the information collected by firms and eventually benefit from better deals in the second period. The analysis of this situation is technically very difficult and is beyond the scope on this article.

One has $\Pi_{p d, i s}^{t o t} \geq \Pi_{p d}^{t o t} \geq \Pi_{u p}^{t o t}$. This result means that the profitability of BBPD is magnified with information sharing. The total welfare being fixed and equal to $2\left(1-(1-\theta)^{3}\right) v$, an important consequence is that consumers are hurt by information sharing in both periods.

\section{Conclusion}

This article has shown that information sharing between rival firms that compete with BBPD can occur in equilibrium and that such an exchange magnifies the profitability of BBPD at the expense of consumers.

This article has implications for privacy regulation. Several qualitative analysis have shown that consumers dislike the practice of targeted pricing. For instance, the Office of Fair Trading argues in its report on targeted advertising and pricing (OFT (2010)) that "a 2005 survey conducted in the US found that 87 percent of respondents objected the practice of online stores charging people different prices, for the same products based on information collected about their shopping habits". The Office of Fair Trading is also concern by the "deterioration in trust in online markets" that behavioral pricing could foster (OFT (2010) $§ \S 5.26$ and 5.27). The current analysis confirms previous results (Esteves (2009a) and Chen and Zhang (2009)) that BBPD with proprietary data can increase firm profits at the expense of consumers but also reaches the novel conclusion that consumers can be even more hurt by behavioral pricing under weak protection of their personal data that could be exchanged between rival firms for price discrimination purposes.

The analysis has also implications for competition policy. It shows that information sharing with BBPD is an equilibrium outcome that can restrict competition without collusion. This means that information sharing among firms that use BBPD may infringe upon article 101(1) of the Treaty on the Functioning of the European Union (TFEU), which prohibits practices 
likely to restrict competition. According to the guideline on the applicability of the Article 101 to horizontal co-operation agreements (European Commission (2010)), customer lists fall into the category "of commercially sensitive, i.e., strategically useful data" that "can give rise to restrictive effects on competition if its reduces the parties' decision making independence by decreasing their incentives to compete". In addition, according to Fine (2010) "it is not necessary for the application of Article 101(1) that the parties engage in bilateral or multilateral exchanges of sensitive information; even a one-way communication may establish liability" ${ }^{11}$, which is exactly the situation that happens in the model developed in this article. Another implication of the analysis is that the anti-competitive effects of an information exchange can occur even before the exchange itself occurs. This is because forward-looking firms that anticipate the extra profits generated by information exchanges will modify their current pricing strategies through higher prices to acquire more valuable information. A practical consequence is that the threat of punishment by competition authorities has to be strong enough to deter firms from even considering the possibility of such consumer-detrimental exchanges, thus preventing them from modifying their current behaviors.

\section{References}

Caillaud, B., De Nijs, R., 2014, "Strategic loyalty reward in dynamic price discrimination", Marketing Science, 33(1), 2014, 725-742

Calzolari, G., and A. Pavan, 2006, "On the optimality of privacy in sequential contracting", Journal of Economic Theory, 130(1), 168-204.

Chen, Y., 1997, "Paying Customers to Switch", Journal of Economics ES Management Strategy, $6(4), 877-897$.

Chen, Y., Narasimhan, C., Zhang, Z.J., 2001, "Individual marketing with imperfect targetability", Marketing Science, 20(1), 23-41.

Chen, Y., 2005, "Oligopoly Price Discrimination by Purchase History", The Pros and Cons of Price Discrimination, The Swedish Competition Authority Stockholm, 101-130.

Chen, Y., Zhang, J.Z., 2009, "Dynamic targeted pricing with strategic consumers", International Journal of Industrial Organization, 27(1), 43-50.

Chen, Y., and J. Pearcy, 2010, "Dynamic Pricing: when to entice brand switching and when to reward consumer loyaly", Rand Journal of Economics, 41(4), 674-685.

\footnotetext{
${ }^{11}$ (See the case Tate and Lyle v. Commission ${ }^{12}$ )
} 
Chen, Y., and He, C., 2011, "Paid-Placement: Advertising and Search on the Internet", Economic Journal, 121(556), 309-328.

Czerny, A., 2009, "Code-sharing, price discrimination and welfare losses", Journal of Transportation Economics and Policy, 43(2), 193-212.

De Nijs, R., 2013, "Information provision and behavior-based price discrimination", Information Economics and Policy, 25(1), 32-40.

De Nijs, R., and A. Rhodes, 2013 "Behavior-based pricing with experience goods", Economics Letters, 118 (1), 155-158.

European Commission, 2010, "Guidelines on the applicability of Article 101 of the Treaty on the Functioning of the European Union to horizontal cooperation", Communication from the Commission, $\operatorname{SEC}(2010)$ 528/2.

Esteves, R.B., 2009a, "Customer poaching and advertising", Journal of Industrial Economics, $57(1), 112-146$.

Esteves, R.B., 2009b, "A Survey on the Economics of Behaviour-Based Price Discrimination", Working Paper.

Esteves, R.B., Vasconcelos, H., 2015, "Price discrimination under consumer recognition and mergers", Journal of Economics and Management Strategy, 24(3), 523-549.

Esteves, R.B. ,2010, "Pricing with Customer Recognition", International Journal of Industrial Organization, 28(6), 669-681.

Fine, F.L., 2010, Information Exchanges Under EU Competition Law: LexisNexis Emerging Issues Analysis, Emerging Issues 5224.

Fudenberg, D., and Tirole, J., 2000, "Customer Poaching and Brand Switching", Rand Journal of Economics, 51(4), 634-657.

Fudenberg, D. and Villas-Boas, J.M., 2007, "Behavior-Based Price Discrimination and Customer Recognition", Hanbook on Economics and information Systems, Hendershott, T.ed North-Holland, Amsterdam, The Nederlands.

Gehrig, T., and Stenbacka, R., 2007, "Information Sharing and Lending Market Competition with Switching Costs and Poaching", European Economic Review, 51(1),77-99.

Jentzsch, N., Sapi, G., Suleymanova, I., 2013, "Targeted pricing and customer data sharing among rivals", International Journal of Industrial Organization, 31(2), 131-144. 
Kim, B.C., Choi, J.P., 2010, "Customer information sharing: strategic incentives and new implications", Journal of Economics 83 Management Strategy, 19(2), 403-433.

Liu, Q., Serfes, K., 2004, "Quality of information and oligopolistic price discrimination", Journal of Economics \& Management Strategy, 13(4), 671-702.

Liu, Q., Serfes, K., 2006, "Customer information sharing among rival firms", European Economic Review, 50(6), 1571-1600.

Narasimhan, C., 1988, "Competitive promotional strategies", Journal of Business, 61(4), 427449.

Office Of Fair Trading, 2010, "Online Targeting of Advertising and Prices", OFT 1231.

Padilla, A., and M. Pagano., 1997, "Endogenous Communication Among Lenders and Entrepreneurial Incentives", Review of Financial Studies, 10(1), 205-236.

Padilla, A., and M. Pagano, 2000, "Sharing Default Information as a Borrower Discipline Device", European Economic Review, 44 (10), 1951-1980.

Pagano, M., and T. Jappelli, 1993, "Information Sharing in Credit Markets", The Journal of Finance, 48 (5), 1693-1718.

Pancras, J., and K. Sudhir, 2007, "Optimal Marketing Strategies for a Customer Data Intermediary", Journal of Marketing Research, 44(4),560-578.

Shaffer, G. and Z.J. Zhang, 2000 "Preference-Based Price Discrimination in Markets with Switching Costs", Journal of Economics EJ Management Strategy, 9(3), 397-442.

Shin, J., and K. Sudhir, 2010, "A Customer Management Dilemma: When Is It Profitable to Reward One's Own Customers?", Marketing Science, 29(4), 671-689.

Shy, O., and Stenbacka, R., 2012, "Customer Privacy and Competition", Working paper.

Shy, O., and Stenbacka, R., 2013, "Investment in customer recognition and information exchange", Information Economics and Policy, 25(2), 92-106.

Stahl, D.O., 1994, "Oligopolistic Pricing and Advertising", Journal of Economic Theory, Elsevier, 64(1), 162-177.

Taylor, C., 2003, "Supplier surfing: competition and consumer behavior in subscription markets", Rand Journal of Economics, 34(2), 223-246.

Taylor, C., 2004, "Consumer Privacy and the Market for Customer Information", Rand Journal of Economics, 35, 631-651. 
Villas-Boas, J.M., 1999, "Dynamic Competition with Customer Recognition", Rand Journal of Economics, 30, 604-631.

\section{A Proof of Proposition 1}

As in Stahl (1994), there does not exist an equilibrium in which all firms use pure strategies. There exists an equilibrium with mixed strategies wherein firms draw their prices according to continuous distribution functions. Let's introduce some notations :

- $F_{i}^{m}($.$) is the price distribution of firm i=s, m, l$ (for small, medium and large firm) in its market $k \in\{o, n\}$ with $o$ that stands for own previous customers and $n$ for new customers.

- $\Pi_{i}$ is the total expected second-period profits of firm $i=s, m, l$.

- $\Pi_{i}^{m}$ is the expected second-period profits of firm $i=s, m, l$ in its market $k \in\{o, n\}$.

The small firm charges two different prices :

- One price to its previous consumers from who it earns a profit $\Pi_{s}^{o}(p)=p \theta(1-\theta)^{2}$. Optimally, the small firm charges its previous customers the monopoly price $v$.

- One price to its new customers from who it earns an expected profit $\Pi_{s}^{n}(p)=p\left(\theta^{2}(1-\right.$ $\left.\theta)\left(1-F_{m}^{o}(p)\right)+\theta^{2}(1-\theta)\left(1-F_{l}^{o, n}(p)\right)+\theta^{3}\left(1-F_{m}^{n}(p)\right)\left(1-F_{l}^{o, n}(p)\right)\right)$. Indeed, there is a fraction $\theta^{2}(1-\theta)$ of consumers who consider both the small and the medium firms' products and they choose to buy to the small firm only when this firm charges a lower price $p$ than the medium one which occurs with probability $\left(1-F_{m}^{o}(p)\right)$. By the same reasoning with the large firm, one can obtain the second term of $\Pi_{s}^{n}(p)$. Last, there is fraction $\theta^{3}$ of consumers who consider all the thres firms' products and they choose to buy to the small firm only when this firm charges a lower price $p$ than the medium and the large ones which occurs with probability $\left.\left(1-F_{m}^{n}(p)\right)\left(1-F_{l}^{o, n}(p)\right)\right)$.

The medium firm charges two prices :

- One price to its previous customers from who it earns an expected profit: $\Pi_{m}^{o}(p)=$ $p\left(\theta(1-\theta)^{2}+\theta^{2}(1-\theta)\left(1-F_{s}^{n}(p)\right)\right)$.

- One price to its new customers from who it earns an expected profit $\Pi_{m}^{n}(p)=p\left(\theta^{2}(1-\right.$ $\left.\theta)\left(1-F_{l}^{o, n}(p)\right)+\theta^{3}\left(1-F_{s}^{n}(p)\right)\left(1-F_{l}^{o, n}(p)\right)\right)$.

The large firm charges only one price (it cannot attract new customers) : 
- One price to its previous customers from who it earns an expected profit $\Pi_{l}^{o, n}(p)=$ $p\left(\theta(1-\theta)^{2}+\theta^{2}(1-\theta)\left(1-F_{m}^{n}(p)\right)+\theta^{2}(1-\theta)\left(1-F_{s}^{n}(p)\right)+\theta^{3}\left(1-F_{m}^{n}(p)\right)\left(1-F_{s}^{n}(p)\right)\right)$.

The construction of the equilibrium runs as follows :

- First step: The medium firm never charges its previous customers a price below $\underline{p}=$ $(1-\theta) v$, as it would be better-off charging $v$ rather than any price below $\underline{p}$. Consequently: $\Pi_{m}^{o}(p)=\Pi_{m}^{o}(v)=\theta(1-\theta)^{2} v$ for all $p \in[\underline{p}, v]$. This yields $F_{s}^{n}(p)$ on $[\underline{p}, v]$.

- Second step: The large firm never charges a price below $\underline{\underline{p}}=(1-\theta)^{2} v$, as it would be betteroff charging $v$ rather than any price below $\underline{\underline{p}}$. Consequently $\Pi_{l}^{o, n}(p)=\Pi_{l}^{o, n}(v)=\theta(1-\theta)^{2} v$ for all $p \in[\underline{\underline{p}}, v]$. This is true in particular for $p \in[\underline{\underline{p}}, \underline{p}]$ where $F_{s}^{n}(p)=0$. This yields $F_{m}^{n}(p)$ on $[\underline{\underline{p}}, \underline{p}]$.

- Third step: Let's assume that the expected profit the medium firm earns from its new customers is $\Pi_{m}^{n}(p)=\theta^{2}(1-\theta) \underline{p}$ for $p \in[\underline{\underline{p}}, \underline{p}]$. This yields $F_{l}^{o, n}(p)$ on $[\underline{\underline{p}}, \underline{p}]$ and by continuation on $[\underline{\underline{p}}, v]$.

- Fourth step: Let's assume that the expected profit the small firm earns from its new customers is $\Pi_{s}^{n}(p)=\theta^{2}(1-\theta)(\underline{p}+\underline{p})$ for $p \in[\underline{p}, v]$. This yields $F_{m}^{o}(p)$ on $[\underline{p}, v]$.

It remains to check that no firm has a profitable deviation from the putative equilibrium constructed above and described in Propostion 1.

The large firm has no profitable deviation. Pricing above $v$ would lead to zero demand and the

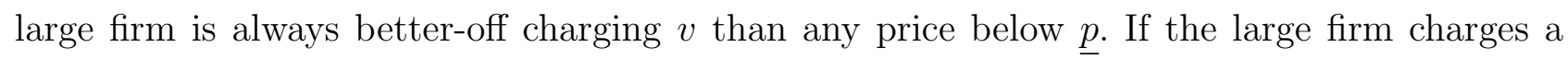
price $p \in[\underline{\underline{p}}, \underline{p}]$ then its profit writes $\Pi_{l}=p\left(\theta(1-\theta)^{2}+\theta(1-\theta)^{2}+\theta^{2}(1-\theta) \frac{1-\theta}{\theta}\left(\frac{(1-\theta) v-p}{p}\right)+\right.$ $\left.\theta^{3} \frac{1-\theta}{\theta}\left(\frac{(1-\theta) \bar{v}-p}{p}\right)\right)=\theta(1-\theta)^{2} v$. If the large firm charges a price $p \in[\underline{p}, v]$, then its profit writes: $\Pi_{l}(p)=p\left(\theta(1-\theta)^{2}+\theta^{2}(1-\theta) \frac{1-\theta}{\theta}\left(\frac{v-p}{p}\right)\right)=\theta(1-\theta)^{2} v$.

By the same reasoning the medium firm has also no incentive to charge a price outside $[\underline{p}, v]$ on its market of previous customers. Let's consider a deviation by the medium firm on its market of new customers. Charging a price strictly below $\underline{\underline{p}}$ would not be profitable as this does not lead to higher demand but decreases its margin. If the medium firm charges a price $p \in[\underline{p}, v]$ to its new customers, then its profit writes: $\Pi_{m}^{n}(p)=\theta^{2}(1-\theta)^{3} v+\theta^{2}(1-\theta)^{3}\left(\frac{v}{p}-1\right)$ which is maximized in $\underline{p}$ where it takes the value $\theta^{2}(1-\theta)^{2} v$, so that the medium firm has no strictly profitable deviation.

Last, let's consider a deviation by the small firm. It is clear that the small firm has no incentive to charge its new customers above $v$ or below $\underline{\underline{p}}$. If the small firm charges its new customers a 
price $p \in[\underline{\underline{p}}, \underline{p}]$, then its profit writes: $\Pi_{s}^{n}(p)=\theta^{2}(1-\theta)^{3} v+\theta^{2}(1-\theta) p+(1-\theta)^{2} \theta^{2} v\left(\frac{(1-\theta) v}{p}-1\right)$ which is $\mathrm{U}$ shape convex function in $p$ on $[\underline{\underline{p}}, \underline{p}]$ and is therefore maximized either at $\underline{\underline{p}}$ or at $\underline{p}$. One has $\Pi_{s}^{n}(\underline{p})=\Pi_{s}^{n}(\underline{p})=\theta^{2}(1-\theta)(\underline{p}+\underline{p})=\theta^{2}(1-\theta)^{2}(2-\theta) v=\theta(1-\theta)^{2}\left(1-(1-\theta)^{2}\right) v$ so that the small firm has no strictly profitable deviation.

\section{B Proof of Proposition 3}

I look for an equilibrium in mixed strategies with continuous distribution functions. Let's introduce some notations :

- $p_{j}^{j}$ is the price charges by firm $i=s, m, l$ (for small, medium and large firm) on the submarket of firm j' previous customers with $j=s, m, l$.

- $F_{j}^{j}($.$) is the distibution used by firm i=s, m, l$ to randomize its price on the submarket of firm j' previous customers with $j=s, m, l$.

- $\tilde{\Pi}_{i}$ is the total expected second-period profits of firm $i=s, m, l$.

- $\tilde{\Pi}_{j}^{j}$ is the expected second-period profits of firm $i=s, m, l$ on the submarket of firm $\mathrm{j}$ ' previous customers with $j=s, m, l$.

The small firm charges three prices :

- One price to its previous customers $p_{s}^{s}=v$.

- One price to the medium firm's previous customers $p_{s}^{m}$ drawn from $F_{s}^{m}($.$) .$

- One price to the large firm's previous customers $p_{s}^{l}$ drawn from $F_{s}^{l}($.$) .$

The medium firm charges two prices :

- One price to its previous customers $p_{m}^{m}$ drawn from $F_{m}^{m}($.$) .$

- One price to the large firm's previous customers $p_{m}^{l}$ drawn from $F_{m}^{l}($.$) .$

The large firm charges one price:

- One price to its previous customers $p_{l}^{l}$ drawn from $F_{l}^{l}($.$) .$

On the submarket of the medium firm's previous customers, expected profits write as follows: 
- $\tilde{\Pi}_{s}^{m}(p)=p \theta^{2}(1-\theta)\left(1-F_{m}^{m}(p)\right)$. Indeed, there is a fraction $\theta^{2}(1-\theta)$ of consumers who consider both the small and the medium firms' products, and they buy to the small firm only when it charges a price $p$ lower than the medium firm's price on its submarket of previous customers which occurs with probability $\left(1-F_{m}^{m}(p)\right)$.

- $\tilde{\Pi}_{m}^{m}(p)=p\left(\theta(1-\theta)^{2}+\theta^{2}(1-\theta)\left(1-F_{s m}(p)\right)\right)$

On this market the equilibrium has been characterized by Narasimhan (1988): the medium firm will never price below $(1-\theta) v$, so that $\tilde{\Pi}_{s}^{m}(p)=\tilde{\Pi}_{s}^{m}((1-\theta) v)$. This yields $F_{m}^{m}(p)=1-\frac{(1-\theta) v}{p}$ on $\left[(1-\theta) v, v\left[\right.\right.$, with a mass $(1-\theta)$ on v. Besides $\tilde{\Pi}_{m}^{m}(p)=\tilde{\Pi}_{m}^{m}(v)$ which yields $F_{s}^{m}(p)=1-\frac{1-\theta}{\theta}\left(\frac{v}{p}-1\right)$ on $[(1-\theta) v, v]$.

On the submarket of the large firm's previous customers, expected profits write as follows:

- $\tilde{\Pi}_{s}^{l}(p)=p\left(\theta^{2}(1-\theta)\left(1-F_{l}^{l}(p)\right)+\theta^{3}\left(1-F_{l}^{l}(p)\right)\left(1-F_{m}^{l}(p)\right)\right)$

- $\tilde{\Pi}_{m}^{l}(p)=p\left(\theta^{2}(1-\theta)\left(1-F_{l}^{l}(p)\right)+\theta^{3}\left(1-F_{l}^{l}(p)\right)\left(1-F_{s}^{l}(p)\right)\right)$

- $\tilde{\Pi}_{l}^{l}(p)=p\left(\theta(1-\theta)^{2}+\theta^{2}(1-\theta)\left(1-F_{s}^{l}(p)\right)+\theta^{2}(1-\theta)\left(1-F_{m}^{l}(p)\right)+\theta^{3}\left(1-F_{s}^{l}(p)\right)\left(1-F_{m}^{l}(p)\right)\right)$

It is clear that $F_{s}^{l}(p)=F_{m}^{l}(p)$ because the small and the medium firms play a symmetric role in this market and that the large firm will never price below $(1-\theta)^{2} v$. Consequently one has $\tilde{\Pi}_{l}^{l}(p)=\tilde{\Pi}_{l}(v)$ which gives $F_{s}^{l}(p)=F_{m l}^{l}(p)=1-\frac{1-\theta}{\theta}\left(\left(\frac{v}{p}\right)^{1 / 2}-1\right)$ on $\left[(1-\theta)^{2} v, v\right]$. Then $\tilde{\Pi}_{s}^{l}(p)=\tilde{\Pi}_{s}^{l}\left((1-\theta)^{2} v\right)$ gives $F_{l}^{l}(p)=\frac{(1-\theta)^{2} v}{p\left((1-\theta)+\theta\left(1-F_{m}^{l}(p)\right)\right)}$ on $\left[(1-\theta)^{2} v, v[\right.$ with a mass $(1-\theta)$ on $v$. Replacing distribution functions in expected profit functions, it is then direct to check than firms have no profitable deviation.

Eventually, one has the following expected second-period profits :

$\tilde{\Pi}_{s}=\theta(1-\theta)^{2} v+2 \theta^{2}(1-\theta)^{2} v$ for the small firm.

$\tilde{\Pi}_{m}=\theta(1-\theta)^{2} v+\theta^{2}(1-\theta)^{2} v$ for the medium firm.

$\tilde{\Pi}_{l}=\theta(1-\theta)^{2} v$ for the large firm. 